\title{
Electrochemical Characterization of Cathodized Copper Oxide Thin Films
}

\author{
T.S. GHADGE ${ }^{\text {a }}$, B. J. LOKHANDE ${ }^{\mathrm{a}, *}$ \\ ${ }^{a}$,School of Physical Sciences, Solapur University, Solapur- 413 255, India \\ *E-mail: bjlokhande@yahoo.com
}

Received: November 21, 2014 | Revised: January 13, 2015 | Accepted: January 17, 2015

Published online: February 10, 2015

The Author(s) 2015. This article is published with open access at www.chitkara.edu.in/publications

\begin{abstract}
Cathodic electrodeposited copper oxide thin films were prepared using $0.1 \mathrm{M}$ aqueous (distilled water) copper sulphate solution onto the surface of stainless steel substrates. Deposited samples were characterized for structural and morphological analysis using XRD and SEM. Prepared samples were also analyzed using cyclic voltammetry, charge discharge and impedance spectroscopy. Electrode shows nearly rectangular capacitive behavior. The highest specific capacitance of $62 \mathrm{~F} / \mathrm{gm}$ was calculated at scan rate $1 \mathrm{mV} / \mathrm{sec}$ in $1 \mathrm{M} \mathrm{Na}_{2} \mathrm{SO}_{4}$ electrolyte. The internal resistance observed from Nyquist plot which is about $1.95 \Omega$. Using ZsimpWin software matched equivalent circuit and circuitry parameters were reported.
\end{abstract}

Keywords: Copper oxide; Cathodization; Electrochemical properties; Impedance

\section{INTRODUCTION}

The energy is the basic requirement of any work. The basic need for development of every country is consumable energy. The collection of energy and storage can be done by using electrochemical supercapacitor, which store energy is in the form of charges. In last few years, electrochemical capacitors have received much more attention in application of energy storage devices due to their high power gain. The existence of capacitance in an electrochemical capacitor was arise from the electrical double layers (electrical double layer capacitance) due to charging and discharging mechanism or from Faradic redox reactions (pseudocapacitance) due to continuous reduction-oxidation process of material [1]. For double layer capacitor, carbon materials of high surface area were used [2]. Consequently, conducting polymers [3], transition metal

\footnotetext{
Journal of Nuclear Physics, Material Sciences, Radiation and Applications Vol. 2, No. 2

February 2015 pp. 159-167
} 
Ghadge, T.S. Lokhande, B.J. oxides with relatively high surface area i.e. $\mathrm{RuO}_{2}$ [4], nickel oxide [5-12], $\mathrm{CoOx}$ [13] and $\mathrm{MnO}_{2}[14,15]$ have been identified as possible electrode material for supercapacitor (pseudo capacitance). Electrochemical supercapacitors are applicable in hybrid electric vehicles, lasers, fuel cells, cellular phones, digital camera etc. Properties of the electrode material decide the cyclability, stability and surface area and rate of redox reaction for ECSC. Alternatively, copper oxide is one of the transition metal oxides having low cost, environmentally compatible and having favorable pseudocapacitive characteristic [16]. Thin films of copper oxide have been prepared by various methods such as solgel, chemical deposition and electrochemical deposition [17-20]. In the present report, synthesis of crystalline copper oxide thin film electrodes by electrodeposition and their electrochemical behavior is reported in depth.

\section{EXPERIMENTAL DETAILS}

Room temperature syntheses of copper oxide thin films were made by cathodic deposition onto the stainless steel substrates in an aqueous $0.1 \mathrm{M} \mathrm{CuSO}_{4}$ solution. The stainless steel substrates (size $1.1 \mathrm{~cm} \mathrm{X} 1.5 \mathrm{~cm}$ ) were first polished with zero grade polish paper and finally washed with double distilled water in an ultrasonic bath for $15 \mathrm{~min}$. Deposition of copper hydroxide thin films were carried out at constant cathodic current density of $60 \mathrm{~mA} / \mathrm{cm}^{2}$. After deposition, thin brown colour copper hydroxide coating gets deposited onto the stainless steel substrates. The obtained sample gets annealed at $623 \mathrm{~K}$ for $1 \mathrm{hr}$.

Weight of the copper oxide deposited on the stainless steel-substrates per unit area $\left(\mathrm{mg} / \mathrm{cm}^{2}\right)$ was measured by gravimetric weight difference method using contact CA 84 five digit microbalance. The internal geometry of the copper oxide was studied by using X-ray diffractometer (Rigaku D/max $2550 \mathrm{Vb}+18 \mathrm{kw}$ with $\mathrm{CuK \alpha}=1.54056 \AA$ ) in the range of diffraction angle $2 \theta$ from $10^{\circ}-100^{\circ}$. The surface morphological analysis was made using a SEM JEOL JSM-6360. Electrochemical properties of the prepared samples were carried out using computer controlled potentiostat (H CH 600AD spl Electrochemical Analyzer/ workstation) with standard three electrode cell having platinum wire as a counter electrode and saturated $\mathrm{Ag} / \mathrm{AgCl}$ as a reference electrode. The charge-discharge behavior of the sample was studied using chronopotentiometric charge-discharge method at different current densities.

\section{RESULTS AND DISCUSSION}

\subsection{Film formation mechanism}

The possible film formation mechanism in cathodic deposition of copper oxide thin film is as fallows: 


$$
\mathrm{CuSO}_{4} .5 \mathrm{H}_{2} \mathrm{O}+\mathrm{H}_{2} \mathrm{O} \longrightarrow \mathrm{Cu}(\mathrm{OH})_{2}+4 \mathrm{H}_{2} \mathrm{O}+\mathrm{H}^{2}+\mathrm{SO}^{2}+\mathrm{O}_{2} \uparrow
$$

After annealing,

$$
\mathrm{Cu}(\mathrm{OH})_{2} \longrightarrow \mathrm{CuO}+\mathrm{H}_{2} \mathrm{O}
$$

As there is a change in oxidation state of copper from +2 to +1 , phase transformation takes place from $\mathrm{CuO}$ to $\mathrm{Cu}_{2} \mathrm{O}$.

\subsection{Structural and morphological study}

The XRD pattern of deposited copper oxide thin film is shown in Fig. 1. Deposited material shows good orientation having polycrystalline behavior with mixed phase of the deposite. Observed ' $d$ ' values matches properly with standard ' $d$ ' values taken from JCPDF data card no.5-667 of $\mathrm{Cu}_{2} \mathrm{O}$ of cubic crystal structure for the orientations along (110), (111), (200) and (311) and 5-661 JCPDF data for $\mathrm{CuO}$ of monoclinic crystal structure for the plane orientations along (100), (111) and (-113). 03-1018 ICPDF data shows $\mathrm{Cu}(\mathrm{III})$ orientation

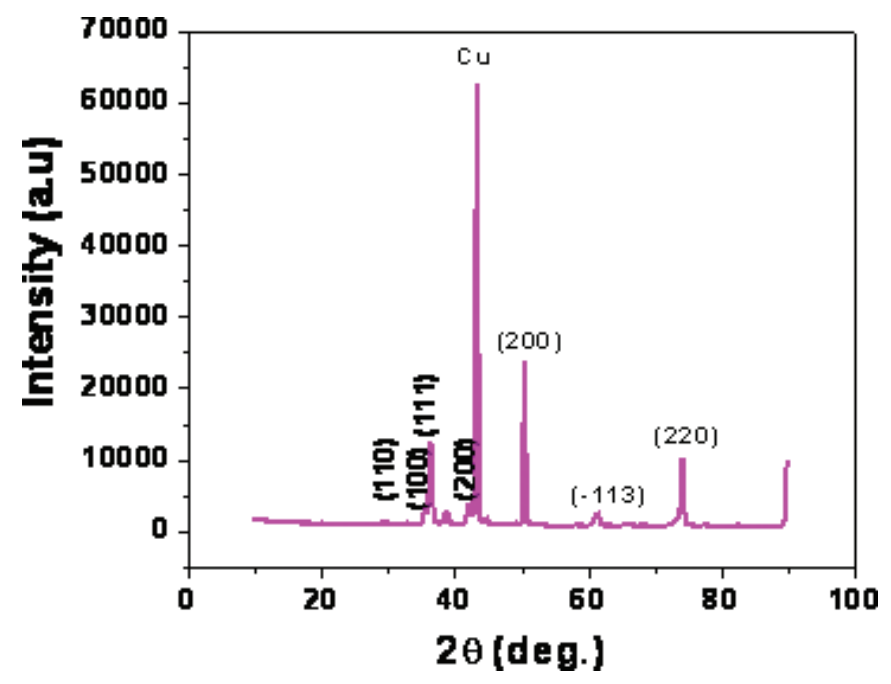

Figure 1: X-ray diffraction spectra of copper oxide deposited on stainless steel.

The observed average value of the crystallite size ' $D$ ' was calculated for predominant (200) plane using Scherrer's formula.

$$
\mathrm{D}=0.9 \lambda / \beta \cos \theta
$$

Electrochemical Characterization of Cathodized Copper Oxide Thin Films 
Ghadge, T.S. Lokhande, B.J.
Where, 0.9 is the Scherrer's constant, $\lambda$ is the wavelength of X-ray, $\beta$ is the fullwidth at half-maximum and ' $\theta$ ' is the diffraction angle. The observed crystallite size for (200) plane was around $27.72 \mathrm{~nm}$.

The surface morphology of the electrodeposited copper oxide thin film taken on the surface of stainless steel substrate is shown in Fig. 2. The deposited material shows more granular surface morphology arranged in densified manner.

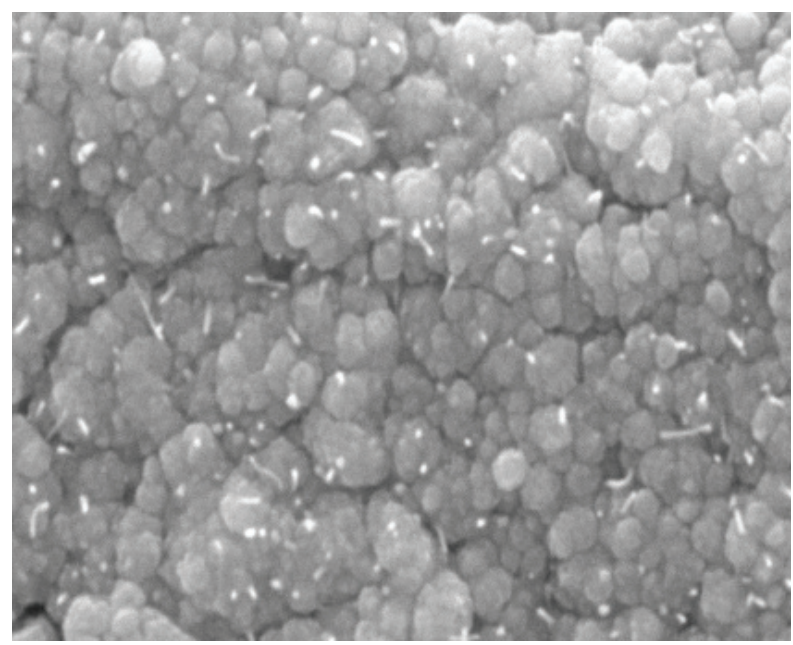

Figure 2: Scanning electron micrograph of copper oxide deposited on stainless steel.

\subsection{Electrochemical properties}

The pseudocapacitive behavior of copper oxide is mainly due to the presence of various oxidation states which causes the redox reactions [12,21]. The pseudocapacitive nature of copper oxide electrode is due to the transition between +2 and +1 oxidation states [16] and vice versa. The electrochemical behavior of the deposited copper oxide was carried out by using cyclic voltammetric measurents. Fig. 3 shows the cyclic voltammograms of copper oxide electrodes within $0.1 \mathrm{~V}$ to $-0.7 \mathrm{~V}$ potential windows. The capacitive behavior of material is due redox transition mechanism.

Capacitance associated with the electrode was calculated for different scan rates by using following relations,

$$
C=\frac{\int I d t}{d V / d t}
$$




$$
S C=\frac{C}{W}
$$

Electrochemical Characterization of Cathodized Copper

Where, $\int$ Idt is the area under curve, $\mathrm{dv} / \mathrm{dt}$ is the voltage scan rate, $\mathrm{C}$ is the Oxide Thin Films capacitance, $\mathrm{W}$ is the weight of the active material dipped in the electrolyte.

The calculated values of SC are given in Table 1. From the Table it is seen that, values of SC decreases with increase in scan rate. The observed maximum value of $\mathrm{SC}$ is $62 \mathrm{~F} / \mathrm{gm}$ at $1 \mathrm{mV} / \mathrm{s}$ scan rate. Chronopotentiometric charge-discharge measurement of the annealed copper oxide electrode was observed at different current densities in $1 \mathrm{M} \mathrm{Na}_{2} \mathrm{SO}_{4}$ electrolyte.

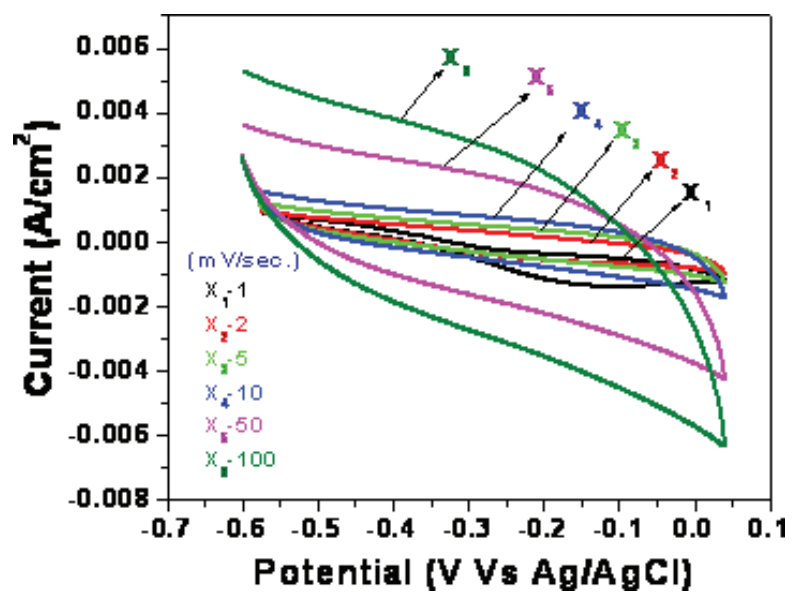

Figure 3: Cyclic voltammograms of copper oxide in $1 \mathrm{M} \mathrm{Na}_{2} \mathrm{SO}_{4}$ at various scan rates.

Table 1: Variation in capacitance and specific capacitance with scan rate for annealed samples.

\begin{tabular}{cccc}
\hline Sr. No. & Scan rate $(\mathbf{m V} / \mathbf{s e c})$ & Capacitance $\left(\mathbf{F} / \mathbf{c m}^{2}\right)$ & Specific capacitance $(\mathbf{F} / \mathbf{g m})$ \\
\hline 1. & 1 & 0.038 & 61.52 \\
2. & 2 & 0.018 & 29.3 \\
3. & 5 & 0.005 & 8.9 \\
4. & 10 & 0.009 & 14.5 \\
5. & 50 & 0.001 & 17.7 \\
6. & 100 & 0.015 & 24.5 \\
\hline
\end{tabular}


Ghadge, T.S. Lokhande, B.J.
Fig. 4 shows charge-discharge variation for annealed copper oxide electrode by varying current density from 0.2 to $5 \mathrm{~mA} / \mathrm{cm}^{2}$. At $5 \mathrm{~mA} /$ $\mathrm{cm}^{2}$, charge-discharge curve shows maximum symmetric nature indicating good reversible nature of the material at that current density. The electrical parameters such as SE, SP and $\eta$ were calculated from charge-discharge curves using the following relations [22].

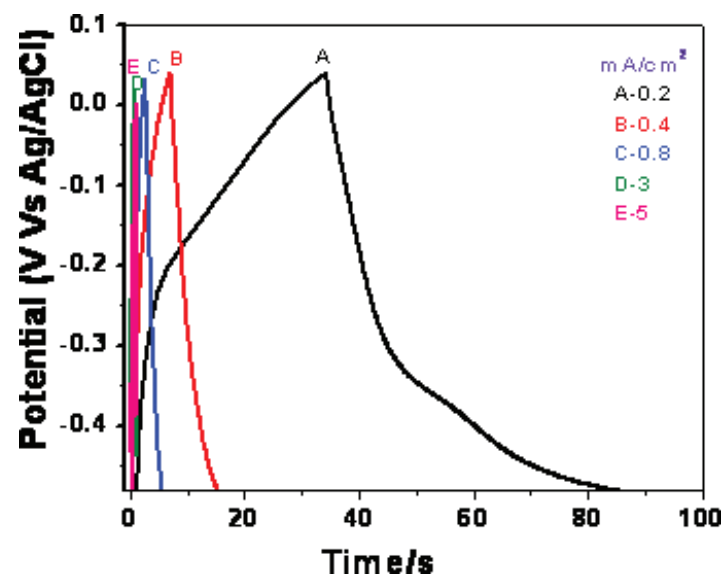

Figure 4: Charge-discharge curves of copper oxide at different current densities.

$$
\begin{gathered}
S E=\frac{V \times I_{d} \times t_{d}}{W} \\
S P=\frac{V \times I_{d}}{W} \\
\eta=\frac{t_{d}}{t_{c}} \times 100
\end{gathered}
$$

Where, $\mathrm{V}$ is the applied voltage, Id and td are the discharging current and time (in hour), $\mathrm{W}$ is the weight of active electrode (in kilogram), tc is the charging time (in hour).

The calculated values of SE, SP and $\eta$ are tabulated in Table. 2, wherein it is observed that at $3 \mathrm{~mA} / \mathrm{cm}^{2}$ current density, electrode shows maximum power output.

Electrochemical impedance measurements were made to search internal resistance of the electrode. Fig. 5(A) shows the Nyquist plot between real 
and imaginary impedance values in the frequency range of $1 \mathrm{mHz}-1 \mathrm{MHz}$, obtained at $-0.1323 \mathrm{~V}$ open circuit potential. At high frequency region, the crossover point of the highest frequency with the real part of the impedance is in general a combine resistance of the electrolyte, intrinsic resistance of substrate and contact resistance between the active material and the current collector. The observed internal resistance was $1.95 \Omega$. Fig.5 (B) (Nyquist plot of Z" vs. Z") shows the experimental and standard curves obtained by simulation using ZsimpWin software; inset of it shows matched equivalent circuit.

Table 2: Variation of Electrical parameters with applied current density.

\begin{tabular}{ccccc}
\hline Sr. No. & $\begin{array}{c}\text { Current Density } \\
(\mathbf{m A} / \mathbf{c m})\end{array}$ & $\begin{array}{r}\text { Specific Energy } \\
(\mathbf{W h} / \mathbf{k g})\end{array}$ & $\begin{array}{c}\text { Specific Power } \\
(\mathbf{k W / k g})\end{array}$ & $\begin{array}{c}\text { Efficiency } \\
(\boldsymbol{\eta}) \%\end{array}$ \\
\hline 1. & 0.2 & 1.59 & 0.096 & 55 \\
2. & 0.4 & 0.491 & 0.192 & 72 \\
3. & 0.6 & 0.375 & 0.298 & 75 \\
4. & 0.8 & 0.346 & 0.385 & 74 \\
5. & 1 & 0.5 & 0.491 & 78 \\
6. & 3 & 0.28 & 1.445 & 85 \\
7. & 5 & 0.202 & 2.4 & 98 \\
\hline
\end{tabular}

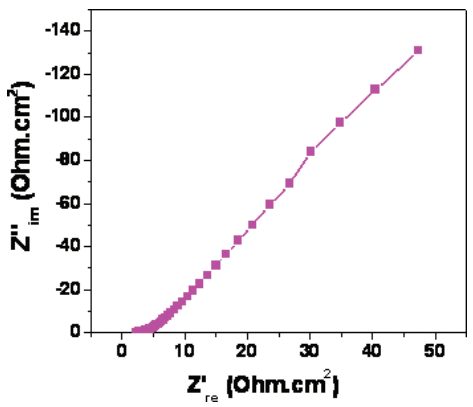

Figure 5 A): Nyquist plot for copper oxide electrode
Electrochemical Characterization of Cathodized Copper Oxide Thin Films

\section{CONCLUSIONS}

Preparation of copper oxide thin film electrodes by cathodic electrodeposition is possible. Deposited material shows mixed phase of crystalline copper oxide. Cyclic voltammograms indicates nearly double layer behaviour. The 
Ghadge, T.S. Lokhande, B.J. prepared electrode gives maximum $62 \mathrm{~F} / \mathrm{gm}$ specific capacitance with specific energy $1.59 \mathrm{Wh} / \mathrm{kg}$, specific power $1.44 \mathrm{~s} \mathrm{~kW} / \mathrm{kg}$ and efficiency $98 \%$. Hence cathodized copper oxide electrode proves a better material for supercapacitor application.

\section{REFERENCES}

[1] K.W Nam, W-S Yoon, K-B Kim, Electrochemica Acta 47 3201, (2002). http://dx.doi.org/10.1016/S0013-4686(02)00240-2

[2] B.E. Conway, J. Electrochem. Soc. 138 1539, (1991). http://dx.doi.org/10.1149/1.2085829

[3] B.E. Conway, Electrochemical Supercapacitor; Scientific Fundamentals and Technological Applications, Kluwer Academic/ Plenum Publishers, New York, 299, (1999).

[4] J.P. Zheng, P.J. Cygan, T.R. Jow, J. Electrochem. Soc. 142 L6 and 2699, (1995). http://dx.doi.org/10.1149/1.2050077.

[5] K.C. Liu, M.A. Anderson, J. Electrochem. Soc. 143 124, (1996). http://dx.doi.org/10.1149/1.1836396

[6] K.C. Liu, M.A. Anderson, Proceedings of the Symposium on Electrochemical Capacitors, in: F.M. Delnick, M. Tomkiewicz (Eds.), PV 95-29, The electrochemical Society Proceedings Series, Pennington, NJ, , p. 68, (1995).

[7] K.C. Liu, M.A. Anderson, Proceedings of the Symposium on Electrochemical Capacitors II, in: F.M. Delnick, D. Ingersoll, X.Andrieu, K. Naoi (Eds.), PV 96-25, The electrochemical Society Proceedings Series, Pennington, NJ, p. 97, (1996).

[8] V. Srinivasan, J.W. Weidner, J. Electrochem. Soc. 144, L210 (1997). http://dx.doi.org/10.1149/1.1837859

[9] V. Srinivasan, J.W. Weidner, J. Electrochem. Soc. 147, 880 (2000). http://dx.doi.org/10.1149/1.1393286

[10] E.E. Kalu, T.T. Nwoga, V. Srinivasan, J.W. Weidner, J. Power Sources 92,163 (2001). http://dx.doi.org/10.1016/S0378-7753(00)00520-6

[11] K.W. Nam, K.B. Kim, Electrochemistry 69, 467 (2001).

[12] W. Nam, K.B. Kim, J. Electrochem. Soc. 149, A346 (2002). http://dx.doi.org/10.1149/1.1449951

[13] C. Zin, J.A. Ritter, B.N. Propov, j. Electrochem. Soc. 145, 4097 (1998). http://dx.doi.org/10.1149/1.1838920

[14] H.Y. Lee, J.B. Goodnough, J.Solid state chem.. 144, 220 (1999). http://dx.doi.org/10.1006/jssc.1998.8128

[15] S.C. Pang, M.A. Anderson, Y.W. Chapman, J. Electrochem. Soc. 147, 444 (2000). http://dx.doi.org/10.1149/1.1393216

[16] J. S. Shaikh, R. C. Pawar, A.V. Mohalkar, J. H. Kim., P. S. Patil Applied Surface Science 257, 4389 (2011). http://dx.doi.org/10.1016/j.apsusc.2010.12.069

[17] L.Armelao, D.barreca, M.Bertapelle, G. Bottaro, C.Sada, Thin solid flims 442, 48 (2003). http://dx.doi.org/10.1016/S0040-6090(03)00940-4 
[18] J.M. Valtriera, S. Calixto, F. Ruiz, Thin film solid 460, 58 (2004).

[19] S.S. Kulakarni, C.D. Lokhande, Trans. SAEST 123 (2003).

[20] P.K. Pandey, S.N. Sahu, S. Chandra, Handbook of semiconductor Electrodepositon, Marcel Dekker, Inc. New York, 237 (1996).

[21] K.R. Prasad, N. Munichandranion, J.Electrochem.Soc.140 446, (1993). http://dx.doi.org/10.1149/1.2221066

[22] B. J. Lokhande, R.C. Ambare, S.R. Bharadwaj, Measurement 47, 427 (2014). http://dx.doi.org/10.1016/j.measurement.2013.09.005
Electrochemical

Characterization of Cathodized Copper Oxide Thin Films 